\title{
РАЗВИТИЕ ПРАКТИКИ МЕНЕДЖМЕНТА ЗАИНТЕРЕСОВАННЫХ СТОРОН В КРУПНЫХ РОССИЙСКИХ КОМПАНИЯХ
}

\author{
(c) 2018 Финогеева Анастасия Игоревна \\ соискатель степени кандидата экономических наук \\ Финансовый университет при Правительстве Российской Федерации \\ 125993, г. Москва, Ленинградский пр-т, д. 49 \\ E-mail: naf413@mail.ru \\ (C) 2018 Батаева Бэла Саидовна \\ доктор экономических наук, доцент \\ Финансовый университет при Правительстве Российской Федерации \\ 125993, г. Москва, Ленинградский пр-т, д. 49 \\ E-mail: bela.bataeva@yandex.ru
}

Исследование содержит результаты анализа практики взаимодействия со стейкхолдерами российских крупнейших компаний, входящих в рейтинг РА-Эксперт-50. В ходе исследования определено, что управление стейкхолдерами может осуществляться централизовано и децентрализовано. Авторы приводят комплекс мер, направленных на совершенствование взаимоотношений компаний со стейкхолдерами. В статье приводится группа показателей, рекомендуемых авторами к раскрытию в нефинансовой отчётности.

Ключевые слова: стейкхолдеры, нефинансовая отчетность, управление стейкхолдерами, корпоративная социальная ответственность, заинтересованные стороны.

В международной практике наблюдается стремительный рост числа компаний, публикующих нефинансовую отчетность с отражением информации по взаимодействию со стейкхолдерами. Растет число стандартов, утверждаемых на национальном и международном уровнях, которые регламентируют системы менеджмента социальной ответственности.

Публикация нефинансовой отчетности стала обязательной для европейских крупных компаний. В соответствии со стратегией развития нефинансовой отчетности в России также ожидается, что нефинансовая отчетность станет обязательной в ближайшие годы. Если для зарубежных компаний взаимодействие со стейкхолдерами является важной частью менеджмента социальной ответственности, то российские компании пока существенно отстают в данном вопросе. Это определило актуальность темы исследования, результаты которого изложены в данной статье.

Развитие концепции заинтересованных стороны связано с работами Р. Акоффа и Р.Э. Фримена [1]. Последний определял стейкхолдеров как лицо или группу лиц, влияющих на функционирование компании и на которых влияет компания [1]. Классификации стейкхолдеров содер- жатся в работах Дж. Поста, Л. Престона и С. Сакса [2], О. Менделоу [3], М. Кларксона [4], Г. Саважа и др. [5] и пр.

Управление стейкхолдерами компании представляет собой управление взаимоотношениями с заинтересованными сторонами, направленное на снижение негативного влияния со стороны окружающих стейкхолдеров и достижение устойчивого развития компании. Данное определение дано с позиции риск-менеджмента.

Управление стейкхолдерами подразумевает планирование мероприятий взаимодействия с заинтересованными сторонами, осуществление взаимодействия на основе принципов прозрачности, открытости и партнерства, а также, оценку удовлетворенности стейкхолдеров [7].

Анализ опыта российских компаний, входящих в рейтинг РА Эксперт-50, по взаимодействию с ключевыми стейкхолдерами корпораций, позволил выявить следующее.

В настоящее время большинство компаний выделяют стейкхолдеров и осуществляют целенаправленное взаимодействие с заинтересованными сторонами. Важным драйвером в распространении менеджмента заинтересованных сторон стала практика публикации нефинансовой отчетности, которая подразумевает помимо 
прочего проведение встреч со стейкхолдерами. Анализ российской практики позволил установить, что она крайне неоднородна и может быть представлена в виде централизованного и децентрализованного управления взаимоотношениями с заинтересованными сторонами компаний.

К централизованному управлению мы относим управление со стороны департамента по корпоративной социальной ответственности или устойчивому развитию. В некоторых случаях может назначаться вице-президент по устойчивому развитию. Децентрализованное управление подразумевает управление взаимоотношениями со стейкхолдерами различными департаментами самостоятельно в рамках своих полномочий. На практике имеет место и смешанный тип управления: децентрализованное управление с элементами централизации, представленное на рисунке 1.

Роль Совета директоров заключается в утверждении стратегии (курса) компании к социальной ответственности (далее КСО)/устой- чивого развития и плана взаимодействия со стейкхолдерами. Роль рабочей группы состоит во внедрении социальной ответственности в управление, системы и процедуры организации, а также в координации процесса взаимодействия разными департаментами со стейкхолдерами компании.

Согласно анализу практики взаимодействия со стейкхолдерами 50-ти крупнейших по объему реализации российских компаний, входящих в рейтинг агентства RAEX («Эксперт-РA), большинство из них составляют нефинансовую отчетность и руководствуются международными стандартами:

1) GRI G4 (Global Reporting Initiative) - Рyководство по отчетности в области устойчивого развития четвертой версии [6] и уже пятой версии (серии отраслевых стандартов);

2) IIRC (International Integral Reporting Council) - Международный стандарт интегрированной отчетности;

3) AA 1000 SES (Stakeholder Engagement Standard) - Стандарт взаимодействия с заинте-

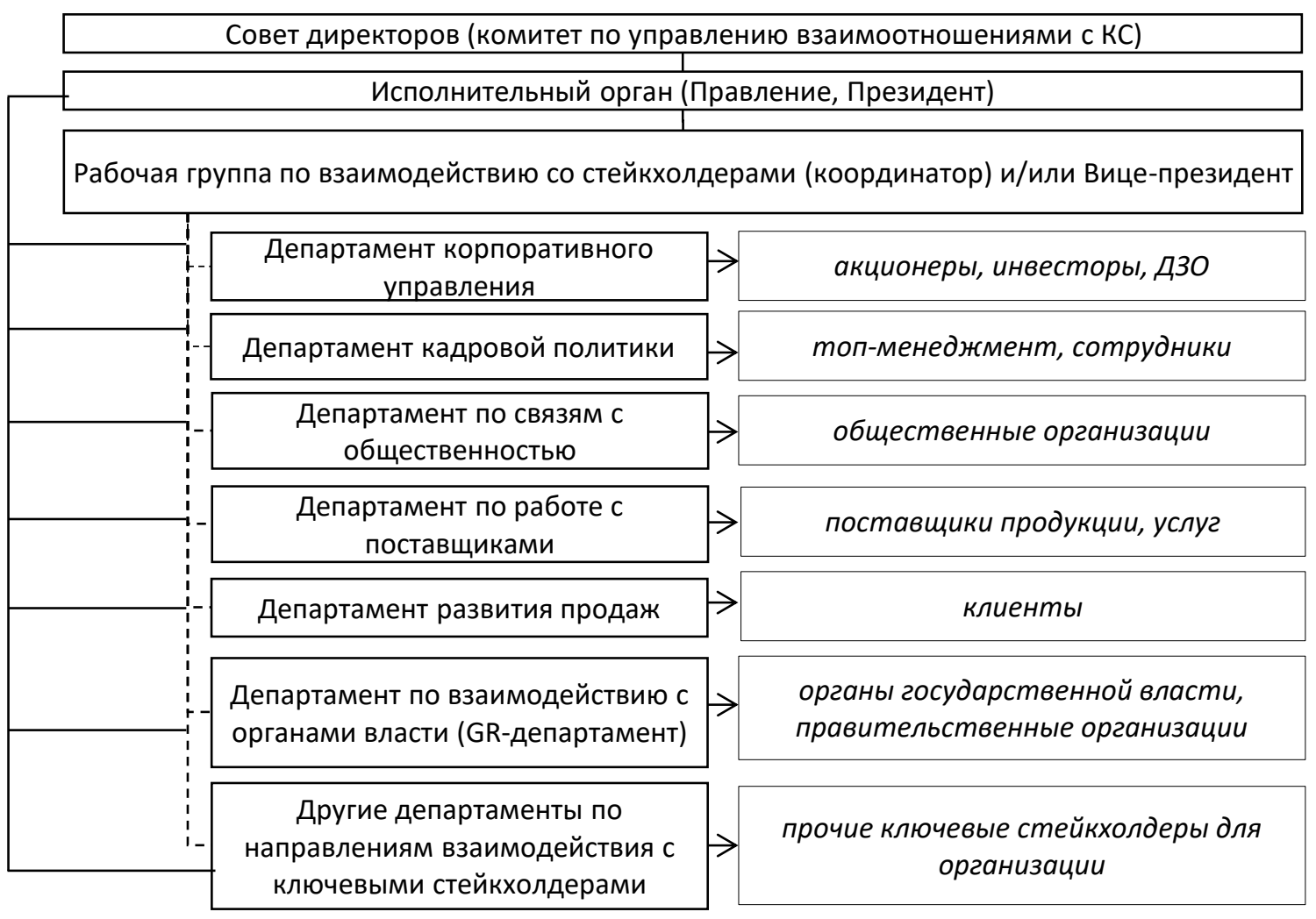

Прямое подчинение
Косвенное подчинение, в рамках координации процесса взаимодействия со стейкхолдерами

Puc. 1. Схема смешанного типа управления стейкхолдерами компании 
ресованными сторонами.

Существует Директива Европейского Союза по нефинансовой отчетности 2014/95/UE от 22.10 .2014 , которая в настоящее время внедрена на законодательном уровне во многих странах Евросоюза. Данный документ подчеркивает, что необходимо в обязательном порядке для повышения доверия стейкхолдеров публиковать информацию о факторах устойчивого развития компании и связанных рисках [8].

Четвертая версия Руководства по отчетности в области устойчивого развития содержит 4 показателя, раскрывающих взаимодействие компании с заинтересованными сторонами (G4-24, G4-25, G4-26, G4-27). Данные показатели регламентируют раскрытие компаниями таких вопросов, как: список стейкхолдеров; принципы отбора стейкхолдеров; частота взаимодействия и ключевые темы взаимодействия.

В ходе проведенного анализа выявлено, что данных раскрытия данных показателей недостаточно, по нашему мнению, данный список может быть расширен (табл. 1):

Раскрытие данной информации позволит повысить прозрачность информации и добиться доверия к компании со стороны широкого круга стейкхолдеров.

Анализ практики позволил выявить, что взаимодействие со стейкхолдерами происходит в соответствии со стандартами: ГОСТ Р ИСО 26000-2012 «Руководство по социальной ответственности», IQNet SR10 «Системы менеджмен- та социальной ответственности. Требования», AA1000 SES «Стандарт взаимодействия с заинтересованными сторонами», ГОСТ Р ИСО 90002015 «Системы менеджмента качества». Примеры документов, регулирующих взаимодействие компании с отдельными группами внутренних и внешних стейкхолдеров, представлены в табл. 2 .

Согласно стандарту IQNet SR10 и AA 1000 SES организации должны регулярно проводить мониторинг информации, относительно удовлетворенности стейкхолдеров.

Оценка результатов взаимодействия компании со стейкхолдерами подразумевает, что структуры, ответственные за взаимодействие со стейкхолдерами периодически осуществляют следующие процедуры:

- выбирают объекты мониторинга;

- определяют методы мониторинга, измерения, анализа и оценки;

- устанавливают сроки проведения измерения (мониторинга);

- утверждают сроки проведения оценки результатов измерения.

Постоянное улучшение взаимодействия с заинтересованными сторонами направлено на повышение устойчивости компании и результативности системы менеджмента социальной ответственности.

Мероприятия, составляющие основу менеджмента взаимодействия со стейкхолдерами, представлены в виде схемы (рисунок 2).

Таблица 1. Показатели, рекомендуемые к раскрытию в нефинансовой отчетности

\begin{tabular}{|l|l|}
\hline \multicolumn{1}{|c|}{ Индекс/показатель } & \multicolumn{1}{c|}{ Содержание } \\
\hline $\begin{array}{l}\text { Группы ключевых стейк- } \\
\text { холдеров (G4-24) }\end{array}$ & $\begin{array}{l}\text { Список групп заинтересованных сторон, с которыми организация взаимодей- } \\
\text { ствует }\end{array}$ \\
\hline $\begin{array}{l}\text { Принципы взаимодействия } \\
(\mathrm{G} 4-25)\end{array}$ & Принципы выявления и отбора заинтересованных сторон для взаимодействия \\
\hline $\begin{array}{l}\text { Подходы к организации } \\
\text { взаимодействия (G 4-26) }\end{array}$ & $\begin{array}{l}\text { Подход организации к взаимодействию с заинтересованными сторонами, } \\
\text { включая частоту взаимодействия по формам и заинтересованным группам, и } \\
\text { сообите, были ли какие-либо элементы взаимодействия предприняты специ- } \\
\text { ально в качестве части процесса подготовки отчета }\end{array}$ \\
\hline Ключевые темы (G4-27) & $\begin{array}{l}\text { Ключевые темы и опасения, которые были подняты заинтересованными сто- } \\
\text { ронами в рамках взаимодействия с организацией, а также то, как организация } \\
\text { отреагировала на эти ключевые темы и опасения, в том числе с помощью под- } \\
\text { готовки своей отчетности. Сообщите, какие группы заинтересованных сторон } \\
\text { подняли каждую из этих тем или высказали каждое из этих опасений }\end{array}$ \\
\hline $\begin{array}{l}\text { Нормативно-правовые } \\
\text { основы взаимодействие }\end{array}$ & $\begin{array}{l}\text { Список основные нормативно-правовые основы взаимодействия с заинтересо- } \\
\text { ванными сторонами (внутрикорпоративные и внешние) }\end{array}$ \\
\hline $\begin{array}{l}\text { Показатели результативно- } \\
\text { сти взаимодействия }\end{array}$ & $\begin{array}{l}\text { Показатели активности взаимодействия (количество проведенных встреч и } \\
\text { др.), результативности взаимодействия с заинтересованными сторонами и } \\
\text { обратной связи (количественная и качественная оценка) }\end{array}$ \\
\hline Каналы взаимодействия & Основные каналы взаимодействия со стейкхолдерами \\
\hline
\end{tabular}


Таблица 2. Нормативно-правовые акты и кодексы, регламентирующие взаимодействие со стейкхолдерами

\begin{tabular}{|c|c|c|}
\hline Стейкхолдеры" & Внутрикорпоративные документы & $\begin{array}{c}\text { Внешние нормативно-правовые акты, } \\
\text { кодексы и стандарты*** }\end{array}$ \\
\hline $\begin{array}{l}\text { Владельцы и акционе- } \\
\text { ры (учредители) }\end{array}$ & $\begin{array}{l}\text { Кодекс корпоративного управления; } \\
\text { Положение об общем собрании акци- } \\
\text { онеров; } \\
\text { Положение о дивидендной политике }\end{array}$ & $\begin{array}{l}\text { Федеральный закон (далее - ФЗ) «Об акцио- } \\
\text { нерных обществах» № 208-ФЗ от 26.12.1995; } \\
\text { ФЗ «О защите прав и законных интересов } \\
\text { инвесторов на рынке ценных бумаг» № 46- } \\
\text { ФЗ от 05.03.1999 }\end{array}$ \\
\hline Сотрудники & $\begin{array}{l}\text { Коллективный договор; } \\
\text { Кодекс корпоративной этики; } \\
\text { Политика управления персоналом; } \\
\text { Положение о развитии персонала }\end{array}$ & $\begin{array}{l}\text { Трудовой кодекс; } \\
\text { ФЗ «О профессиональных союзах, их пра- } \\
\text { вах и гарантиях деятельности» № 10-ФЗ от } \\
\text { 12.01.1996; } \\
\text { Конвенции Международной организации } \\
\text { труда }\end{array}$ \\
\hline $\begin{array}{l}\text { Клиенты, пользовате- } \\
\text { ли и потребители }\end{array}$ & $\begin{array}{l}\text { Порядок рассмотрения претензий; } \\
\text { Стандарты качества }\end{array}$ & $\begin{array}{l}\text { Закон РФ «О защите прав потребителей» } \\
\text { № 2300-1 от 07.02.1992 }\end{array}$ \\
\hline $\begin{array}{l}\text { Поставщики продук- } \\
\text { ции, поставщики услуг } \\
\text { и партнеры }\end{array}$ & $\begin{array}{l}\text { Положение об организации договор- } \\
\text { ной работы; } \\
\text { Положение о закупках }\end{array}$ & $\begin{array}{l}\text { Ф3 «О закупках товаров, работ, услуг отдель- } \\
\text { ными видами юридических лиц» № 223-Ф3 } \\
\text { от 18.07.2011 (применяется большинством } \\
\text { крупных российских компаний) } \\
\text { ISO } 20400 \text { «Устойчивые закупки» }\end{array}$ \\
\hline $\begin{array}{l}\text { Органы государ- } \\
\text { ственного и местного } \\
\text { управления и власти, } \\
\text { регулирующие } \\
\text { Органы }\end{array}$ & $\begin{array}{l}\text { Соглашения о сотрудничестве; } \\
\text { Социально-экономические проекты; } \\
\text { Политика компании в области про- } \\
\text { тиводействия коррупции }\end{array}$ & $\begin{array}{l}\text { Ф3 «О государственно-частном партнерстве, } \\
\text { муниципально-частном партнерстве в Рос- } \\
\text { сийской Федерации» № 224-ФЗ от 13.07.2015; } \\
\text { ФЗ «О государственной регистрации юриди- } \\
\text { ческих лиц и индивидуальных предприни- } \\
\text { мателей» № 129-ФЗ от 08.08.2001; } \\
\text { Ф3 «О лицензировании отдельных видов } \\
\text { деятельности» № 99-Ф3 от 04.05.2011; } \\
\text { ИСО 37001:2016 Система менеджмента про- } \\
\text { тиводействия коррупции }\end{array}$ \\
\hline $\begin{array}{l}\text { Местное сообщество, } \\
\text { общественность и } \\
\text { общественные орга- } \\
\text { низации }\end{array}$ & $\begin{array}{l}\text { Положение об участии в обществен- } \\
\text { ных организациях; } \\
\text { Политика по работе с местными } \\
\text { сообествами }\end{array}$ & $\begin{array}{l}\text { Ф3 «Об основах общественного контро- } \\
\text { ля в Российской Федерации» № 212-ФЗ от } \\
21.07 .2014 ; \\
\text { Декларация ООН «О правах коренных наро- } \\
\text { дов»; } \\
\text { ФЗ «О некоммерческих организациях» } \\
\text { № 7-ФЗ от 12.01.1996; } \\
\text { Ф3 «О благотворительной деятельности и } \\
\text { добровольчестве (волонтерстве)» № } 135 \text {-Ф3 } \\
\text { от 11.08.1995 }\end{array}$ \\
\hline $\begin{array}{l}\text { Окружающая среда и } \\
\text { организации, связан- } \\
\text { ные с окружающей } \\
\text { средой }\end{array}$ & Экологическая политика компании & $\begin{array}{l}\text { ФЗ «Об охране окружающей среды» № 7-ФЗ } \\
\text { от 10.01.2002 и прочее природоохранное } \\
\text { законодательство; } \\
\text { Экологические стандарты } \\
\text { (ГОСТ Р ИСО 14015-2007 Экологический ме- } \\
\text { неджмент, ГОСТ Р ИСО 50001-2012 Системы } \\
\text { энергетического менеджмента и др.) }\end{array}$ \\
\hline Конкуренты & Кодекс корпоративной этики & $\begin{array}{l}\text { Ф3 «О защите конкуренции» от 26.07.2006 } \\
\text { № 135-Ф3 } \\
\text { ИСО 37001:2016 Система менеджмента про- } \\
\text { тиводействия коррупции }\end{array}$ \\
\hline
\end{tabular}

* Список стейкхолдеров составлен в соответствии со стандартом IQNet SR10 «Системы менеджмента социальной ответственности. Требования» [9].

** Содержат законодательные требования, применимые к организации, а также требования систем менеджмента. 
Утверждение стратегии в области КСО и управления стейкхолдерами с утверждением целевых показателей;

Формирование рабочей группы для обеспечения организации взаимодействия со стейкхолдерами (или обязательное наличие данной функции в существующей рабочей группе по подготовке нефинансовой отчетности);

Использование методики идентификации ключевых стейкхолдеров, включая создание единой информационной корпоративной базы с информацией о стейкхолдерах компании, их интересах и формирование плана мероприятий взаимодействия по наиболее существенным вопросам;

Применение активных стратегий взаимодействия с заинтересованными сторонами и соответствующих им инструментов вовлечения и сотрудничества со стейкхолдерами;

Расширение способов раскрытия информации путем публикации нефинансовой отчетности в соответствии со стандартами GRI, IIRC и AA1000 SES и пр;

Осуществление оценки результативности взаимодействия со стейкхолдерами в соответствии с утвержденными целевыми показателями и актуализация плана мероприятий (каждые 6 месяцев).

Puc. 2. Комплекс мер по совершенствованию управления заинтересованными сторонами

После оценки результативности взаимодействия в случае обнаружения несоответствия предпринимают корректирующие действия: на основе полученных результатов проводится корректировка политики взаимодействия с заинтересованными сторонами.

Данный комплекс мер предназначен для совершенствования взаимоотношений компаний со стейкхолдерами с целью повышения устойчивости компании и результативности менеджмента социальной ответственности. Они представляют собой элементы системы качественного взаимодействия с заинтересованны- ми сторонами, реализуемого компаниями в соответствии с международными стандартами ISO 26000, IQNet SR10 и AA 1000 SES.

Таким образом, сформулированные в данной статье предложения по совершенствованию управления стейкхолдерами являются частью системы менеджмента социальной ответственности. Их внедрение в практику российских компаний позволит добиться повышения доверия со стороны внутренних и внешних стейкхолдеров. Это будет способствовать повышению конкурентоспособности и устойчивости российских компаний.

\section{Библиографический список}

1. Freeman R.E. Strategic Management: A Stakeholder Approach....-Boston. 1984. 275 p.

2. Post J.E., Preston L.E., Sachs S. Managing the extended enterprise: The new stakeholder view// California Management Review, Vol. 45 (1). 2002. P. 5-28. 
3. Mendelow A., Stakeholder Mapping // Proceedings of the 2nd International Conference on Information Systems. 1991, Cambridge. MA.

4. Clarkson M.B.E. A Stakeholder framework for analyzing and Evaluating Corporate Social Performance // Academy of Management Review, Vol. 20 № 1. 1995. P. 92-118.

5. Savage, G.T., Nix, T.W., Whitehead, C.J., Blair, J.D. Strategies for assessing and managing organizational stakeholders // Academy of Management Executive. 5(2). 1991. P. 61-75.

6. Руководство GRI по отчетности в области устойчивого развития версии G4 [Электронный ресурс] // Официальный сайт GRI (Глобальной инициативы по отчетности). - Режим доступа: https://www.globalreporting. org/standards/g4.

7. Финогеева А.И., Батаева Б.С. Совершенствование управления взаимоотношениями с ключевыми стейкхолдерами корпорации // Российский экономический интернет-журнал [Электронный ресурс]. 2017. № 3. Режим доступа: http://www.e-rej.ru/Articles/2017/Finogeeva_Bataeva.pdf.5.

8. Батаева, Б.С. Управление заинтересованными сторонами компаний: теоретико-методический аспект // Проблемы теории и практики управления. 2018. № 5. С. 80-88.

9. Стандарт IQNet SR10 «Системы менеджмента социальной ответственности. Требования» [Электронный ресурс] // Официальный сайт Международной сети по сертификации.- Режим доступа: http://www.iqnetcertification.com/userfiles/SR\%2010/SR10_IQNet_2015_RU.pdf. 